\title{
Deposição de tecidos e componentes químicos corporais em bovinos Nelore de diferentes classes sexuais ${ }^{1}$
}

\section{Pedro Veiga Rodrigues Paulino², Sebastião de Campos Valadares Filho², Edenio Detmann², Rilene Ferreira Diniz Valadares ${ }^{3}$, Mozart Alves Fonseca ${ }^{4}$, Marcos Inácio Marcondes ${ }^{5}$}

\author{
1 Pesquisa financiada pelo CNPq \\ ${ }^{2}$ DZO/UFV, Viçosa, MG. \\ ${ }^{3}$ DVT/UFV, Viçosa, MG. \\ ${ }^{4}$ Curso de Agronomia, UFV. Bolsista de Iniciação Científica PIBIC/CNPq \\ 5 Programa de Pós-Graduação em Zootecnia - DZO/UFV.
}

RESUMO - Objetivou-se avaliar os efeitos de classe sexual e nível de oferta de concentrado (0,6 e 1,2\% do peso vivo) sobre a composição corporal e a deposição dos principais tecidos e constituintes químicos do corpo vazio de bovinos Nelore de diferentes classes sexuais (machos não-castrados, machos castrados e fêmeas). Foram utilizados 35 animais, alimentados individualmente durante 112 dias e abatidos. Um grupo-referência foi abatido ao início do experimento, com peso inicial médio de $338 \mathrm{~kg}$ (machos não-castrados); $308 \mathrm{~kg}$ (machos castrados) e 287,5 kg (fêmeas). Os pesos corporais iniciais e de abate ao final do experimento foram, respectivamente, de 345,3 e 435,0 kg para os machos não-castrados; 328,3 e 396,0 para os machos castrados; e 303,9 e 372,0 kg para as fêmeas. A participação da gordura visceral e subcutânea em relação ao peso de corpo vazio total nas fêmeas foi maior, apesar de as taxas de deposição de gordura não terem sido influenciadas pela classe sexual. O nível de oferta de concentrado não afetou a composição corporal de bovinos Nelore. Machos não-castrados apresentaram maior e menor conteúdo de proteína e gordura, respectivamente, no corpo vazio e no ganho de peso de corpo vazio, em relação aos machos castrados e às fêmeas. A taxa de deposição de proteína no corpo vazio foi maior nos machos não-castrados em relação às fêmeas e aos machos castrados, enquanto a taxa de deposição de gordura corporal não diferiu entre as classes sexuais A classe sexual afeta a deposição dos constituintes do corpo vazio de bovinos Nelore.

Palavras-chave: bovinos de corte, composição corporal, gordura, músculo

\section{Body tissue and chemical component deposition in Nellore bulls, steers and heifers}

\begin{abstract}
The objective on this study was to assess the effects of gender and concentrate allowance level (0.6 and $1.2 \%$ body weight) on body composition and deposition of the main body tissues and chemical components of the empty body weight in Nellore cattle of different gender (bulls, steers and heifers). Thirty five animals were used, fed individually for 112 days, and then slaughtered. A reference group was slaughtered at the beginning of the trial, with average body weight of $338 \mathrm{~kg}$ (bulls), $308 \mathrm{~kg}$ (steer) and $287.5 \mathrm{~kg}$ (heifers). The initial body weight and final slaughter weight of the animals were, respectively, 345.3 and $435.0 \mathrm{~kg}$ for the bulls, 328.3 and $396.0 \mathrm{~kg}$ for the steer and 303.9 and $372.0 \mathrm{~kg}$ for the heifers. The percentage of visceral and subcutaneous fat in the empty body weight was greater in the heifers, although the fat deposition rates were not influenced by gender. The concentrate allowance level did not affect the body composition of Nellore cattle. Bulls had greater and lower protein and fat content, respectively, in the empty body and in the empty body gain than the steers and heifers. The protein deposition rate in the empty body was greater for the bulls compared to the heifers and steers, while the fat deposition rate did not differ among the genders. Gender affects the deposition of carcass and empty body constituents of Nellore cattle.
\end{abstract}

Key Words: beef cattle, body composition, fat, muscle

\section{Introdução}

A composição corporal em bovinos de corte, determinada pela composição química de seus principais componentes, como proteína, gordura, minerais e água, é de extrema relevância para o entendimento da eficiência nos sistemas de produção. Assim, a determinação da composição corporal torna-se de grande importância em 
estudos que avaliem alimentos ou o crescimento em si (Bonilha et al., 2007), que busquem determinar as exigências nutricionais dos animais (Valadares Filho et al., 2005) ou que procurem identificar os principais fatores que afetam a deposição dos tecidos corporais. Além disso, o conhecimento sobre o padrão de deposição dos principais constituintes corporais permite tomar uma série de decisões gerenciais de grande impacto econômico dentro dos diferentes sistemas de produção.

Vários fatores de ordem genética e ambiental influenciam o padrão de deposição dos tecidos e constituintes corporais e, consequentemente, a composição corporal de bovinos de corte, com destaque para grupo genético, idade, classe sexual enível nutricional (Lohman, 1971; Coleman et al., 1993). Animais não-castrados tendem a apresentar maior taxa de crescimento, com composição do ganho caracterizada por maior teor de proteína e menos gordura, resultando em maior eficiência alimentar, quando comparados a animais castrados ou fêmeas, dentro de um mesmo grupo contemporâneo (Purchas, 1991). O plano nutricional também afeta a composição corporal, sobretudo o consumo de energia, embora a interpretação dos resultados obtidos na literatura seja variável (Old \& Garrett, 1987). Muito pouco se conhece, no entanto, sobre os efeitos de classe sexual e nível energético da dieta, bem como sua interação, sobre o crescimento e a composição corporal de bovinos Nelore no Brasil. Além disso, embora pareça haver um consenso de que bovinos Nelore são mais eficientes em situações de dietas mais pobres em energia (Putrino et al., 2007; Oliveira et al., 1991; Hunter \& Siebert, 1985), poucos estudos procuraram estudar o padrão de deposição dos principais constituintes corporais em tourinhos, novilhos e novilhas Nelore, submetidos à dietas de alta e baixa energia.

A gordura corporal é o item que mais varia, enquanto a massa seca livre de gordura é bastante constante (NRC, 2000), visto que a principal mudança na composição corporal que ocorre com o crescimento e desenvolvimento animalé o aumento no conteúdo de gordura (Williams, 2005). Kempster (1981) citou que existe número limitado de informações sobre as diferenças entre classes sexuais quanto à partição entre os diferentes depósitos de gordura corporais em bovinos. Sabe-se muito pouco sobre os principais locais de acúmulo de gordura em genótipos zebuínos (Sprinkle et al., 1998). Nesse sentido, torna-se relevante estudar o padrão de acréscimo dos depósitos de gordura corporal nos animais, tendo em vista a classe sexual e o nível de oferta de concentrado.

Nesse sentido, objetivou-se estudar os efeitos de classe sexual e nível de oferta de concentrado sobre a composição corporal e o padrão de deposição dos principais tecidos e constituintes químicos do corpo vazio de bovinos Nelore de diferentes classes sexuais.

\section{Material e Métodos}

O experimento foi realizado no confinamento experimental do Laboratório Animal do Departamento de Zootecnia da Universidade Federal de Viçosa entre os meses de outubro de 2004 a janeiro de 2005.

Foram utilizados 35 animais (12 machos não-castrados, 11 machos castrados e 12 fêmeas) com peso corporal médio ao iníco do experimento de 345,3;328,3 e 303,9 kg e espessura de gordura subcutânea, mensurada via ultrassonografia na região entre a $12 \underline{a}$ e $13 \underline{a}$ costelas, de 2,$30 ; 2,66$ e 2,98 mm, respectivamente. Os animais vieram de um mesmo rebanho comercial e foram utilizados em experimento prévio, no qual foram alimentados com mesma dieta (11,80\% de PB e 56,90\% de NDT) durante 77 dias. Imediatamente após o término desse período, 11 animais (4 machos não-castrados, 3 machos castrados e 4 fêmeas) foram abatidos, de forma a comporem o grupo-referência, que foi utilizado para estimação da composição inicial do corpo vazio e da carcaça dos demais animais. $\mathrm{O}$ abate foi realizado após jejum de sólidos de 16 horas.

Os animais remanescentes permaneceram alojados no confinamento experimental, em baias individuais, com dimensões de $1,8 \mathrm{~m}$ de largura por $18,8 \mathrm{~m}$ de comprimento, totalizando $33,84 \mathrm{~m}^{2}$. Desse total, $11,88 \mathrm{~m}^{2}(1,8 \times 6,6 \mathrm{~m})$ eram de piso de concreto e cobertos com telha de amianto. Cada baia era provida de comedouro $(1,6 \mathrm{~m})$ e bebedouro de concreto.

O delineamento experimental utilizado foi o inteiramente casualizado, em esquema fatorial $3 \times 2$, respectivamente, com três classes sexuais (machos nãocastrados, machos castrados e fêmeas) e dois níveis de oferta de concentrado ( $0,6 \%$ e $1,2 \%$ do peso), compondo, portanto, 6 tratamentos.

Os animais foram adaptados às dietas experimentais durante uma semana. As dietas foram formuladas de forma a serem isoproteicas, utilizando-se silagem de milho como alimento volumoso. Os concentrados experimentais foram formulados com fubá de milho, farelo de algodão $42 \%$ de PB, ureia:sulfato de amônio (9:1), calcáreo calcítico, cloreto de sódio (sal branco) e mistura mineral comercial (Tabela 1).

O experimento teve duração de 112 dias, subdividos em quatro períodos experimentais de 28 dias. A dieta foi fornecida em duas vezes, às $6 \mathrm{~h} 30$ e $15 \mathrm{~h} 30$, com cerca de $60 \%$ da quantidade diária fornecida pela manhã e os $40 \%$ 
Tabela 1 - Composição dos concentrados experimentais, na base da matéria natural

\begin{tabular}{lcc}
\hline Ingrediente (\%) & Nível de concentrado (\% do PV) \\
\cline { 2 - 3 } & 0,6 & 1,2 \\
\hline Fubá de milho & 58,9 & 83,2 \\
Farelo de algodão 42\% PB & 33,9 & 13,2 \\
Ureia/sulfato de amônio & 3,0 & 1,50 \\
Calcário calcítico & 2,0 & 1,0 \\
Cloreto de sódio & 1,1 & 0,55 \\
Mistura mineral ${ }^{1}$ & 1,1 & 0,55 \\
\hline${ }^{1}$ Composição da mistura mineral, por kg do produto: cálcio, 240 g; fósforo, $174 \mathrm{~g} ;$ \\
cobalto, 100 mg; cobre, 1.250 mg; ferro, 1.795 mg; flúor (máximo), 1.740 mg; \\
iodo, 90 mg; manganês, 2.000 mg; zinco, 5.270 mg; selênio, 15 mg; veículo \\
q.s.p., 1.000 g.
\end{tabular}

restantes na parte da tarde. A quantidade de concentrado fornecida foi ajustada a cada 28 dias, quando os animais eram pesados, e todas as pesagens foram realizadas após jejum de sólidos de 16 horas.

Amostras da silagem de milho foram obtidas diariamente, compostas por semana, pré-secas, moídas e armazenadas. Dessa forma, o volumoso utilizado foi analisado semanalmente. Os ingredientes dos concentrados (milho e farelo de algodão) foram coletados a cada partida, totalizando três amostras de cada ingrediente ao longo do experimento. As amostras da silagem de milho e dos ingredientes dos concentrados (fubá de milho e farelo de algodão) foram analisadas em laboratório quanto aos seus teores de matéria seca (MS), matéria mineral (MM), nitrogênio total e extrato etéreo (EE), seguindo as recomendações de Silva \& Queiroz (2002). A matéria orgânica foi obtida como sendo 100-MM, e o teor de proteína bruta (PB) a partir do produto do $\mathrm{N}$ total e o fator 6,25. Os teores de fibra em detergente neutro (FDN) e nitrogênio insolúvel em detergente neutro (NIDN) foram obtidos de acordo com os protocolos descritos por Van Soest et al. (1991) e Licitra et al. (1996). A fibra em detergente ácido, o nitrogênio insolúvel em detergente ácido (NIDA) e a lignina (LIG) (ácido sulfúrico 72\%) foram obtidos segundo Van Soest \& Robertson (1980) e Licitra et al. (1996). Utilizou-se o sistema ANKOM para as avaliações de FDN e FDA, com modificação do saquinho utilizado $(5,0 \times 5,0 \mathrm{~cm}$, porosidade de $100 \mu \mathrm{m})$, que foi confeccionado utilizando-se tecido (TNT $-100 \mathrm{~g} / \mathrm{m}^{2}$ ). Alpha-amilase estável ao calor foi empregada nas análises de FDN, cujas amostras dos alimentos não foram corrigidas para cinzas.

Os carboidrados não-fibrosos (CNF) foram calculados de acordo com o NRC (2001), como: CNF (\%) $=100-(\%$ PB $+\% \mathrm{EE}+\%$ cinzas $+(\% \mathrm{FDN}-\% \mathrm{PIDN}))$. Para os concentrados, em virtude da presença de ureia em suas constituições, o teor de CNF foi calculado como proposto por Hall (2000): $\mathrm{CNF}=100-((\% \mathrm{~PB}-\% \mathrm{~PB}$ derivada da ureia $+\%$ de ureia $)$ $+\% \mathrm{FDNp}+\% \mathrm{EE}+\%$ cinzas $)$.
A densidade energética das dietas experimentais, expressa em nutrientes digestíveis totais (NDT), foi determinada a partir da fórmula recomendada pelo NRC (2001): NDT $(\%)=\mathrm{PBD}+2,25 \times \mathrm{EED}+\mathrm{CNFD}+\mathrm{FDNpD}, \mathrm{em}$ que PBD, EED, CNFD e FDNpD significam, respectivamente, proteína bruta digestível, extrato etéreo digestível, carboidratos não-fibrosos digestíveis e fibra em detergente neutro (isenta de proteína) digestível. A concentração de energia digestível (ED) das dietas foi obtida pela equação proposta pelo NRC (2001): $\mathrm{ED}(\mathrm{Mcal} / \mathrm{kg} \mathrm{MS})=5,6 \times \mathrm{PBD}+$ $9,4 \times \mathrm{EED}+4,2 \times \mathrm{FDNpD}+4,2 \times \mathrm{CNFD}$. As concentrações de energia metabolizável (EM) foram consideradas como $82 \%$ da ED (NRC, 2000).

Ensaios de digestibilidade foram realizados em cada período experimental, sempre em seu terço médio, ou seja, ao final da segunda semana de cada período de 28 dias. Durante os ensaios, foram coletadas amostras de fezes de cada animal em dois dias consecutivos, diretamente no piso das baias e imediatamente após a defecação. No primeiro dia, as fezes foram coletadas no período da manhã e no dia subsequente no período da tarde. As amostras de fezes foram acondicionadas em pratos de alumínio e levadas à estufa de ventilação forçada a $65^{\circ} \mathrm{C}$, durante 72 horas. Depois de secas, foram moídas em moinho com peneira de $1 \mathrm{~mm}$ e, em seguida, acondicionadas em recipientes de plástico. Para cada animal, e por período, foram obtidas duas amostras de fezes (manhã e tarde), que foram proporcionalmente homogeneizadas, depois de secas e moídas, formando amostra composta. Desta forma, ao longo de todo o período experimental obtiveram-se quatro amostras compostas de fezes para cada animal.

A excreção fecal foi estimada a partir da técnica do indicador interno, conforme Cochran et al. (1986), utilizando-se a fibra em detergente ácido indigestível (FDAi). Os teores de FDAi nas amostras de fezes, sobras e dos alimentos fornecidos (silagem de milho e concentrados) foram obtidos como sendo o resíduo resultante após tratamento das amostras - incubadas in situ por um período de 144 horas - com detergente ácido (FDA). As digestibilidades da matéria seca, da matéria orgânica e de todos os demais nutrientes analisados (PB, EE, CNF e FDN) foram obtidas a partir do consumo e da excreção desses nutrientes. Como foram realizados quatro ensaios de digestibilidade ao longo do experimento, obtiveram-se as médias das digestibilidades, as quais foram utilizadas para calcular a densidade energética das dietas (Tabela 2).

Ao final do experimento, que foi determinado por tempo fixo de confinamento (112 dias), e não peso de abate, os animais foram pesados, após jejum de sólidos de 16 horas, e abatidos em seguida, por concussão cerebral, seguida de 
Tabela 2 - Composição química dos alimentos e das dietas experimentais, expressos na base da matéria seca

\begin{tabular}{|c|c|c|c|c|c|}
\hline Item & Silagem de milho & Fubá de milho & Farelo de algodão & $\mathrm{D} 1-0,6 \%$ & $\mathrm{D} 2-1,2 \%$ \\
\hline Matéria seca, \% & 24,34 & 87,13 & 87,02 & 40,25 & 55,95 \\
\hline Matéria orgânica, \% MS & 94,46 & 98,88 & 93,52 & 94,44 & 94,80 \\
\hline Proteína bruta, \% MS & 6,17 & 9,07 & 46,87 & 12,06 & 12,10 \\
\hline NIDA, \% do $\mathrm{N}$ total & 8,87 & 3,82 & 2,11 & 7,39 & 6,16 \\
\hline Extrato etéreo, \% MS & 2,77 & 3,32 & 2,80 & 2,80 & 2,95 \\
\hline Fibra em detergente neutro, $\% \mathrm{MS}$ & 60,87 & 12,43 & 31,94 & 50,15 & 37,68 \\
\hline Fibra em detergente ácido, \% MS & 37,49 & 3,57 & 25,23 & 30,76 & 21,88 \\
\hline Lignina, \% MS & 5,05 & 0,76 & 9,41 & 4,69 & 3,46 \\
\hline Nutrientes digestíveis totais, $\%$ & - & - & - & 62,41 & 67,91 \\
\hline Energia digestível, Mcal/kg MS & - & - & - & 2,72 & 2,95 \\
\hline Energia metabolizável, Mcal/kg MS & - & - & - & 2,23 & 2,42 \\
\hline
\end{tabular}

NIDA = nitrogênio insolúvel em detergente ácido; NIDN = nitrogênio insolúvel em detergente neutro; FDNcp = fibra em detergente neutro corrigida para cinzas e proteína D1 - $0,6 \%$ - Dieta composta por aproximadamente $75 \%$ de silagem de milho e $25 \%$ de concentrado ou $0,6 \%$ do PV em concentrado, na base da matéria seca total, D2 - 1,2\% - Dieta composta aproximadamente por $50 \%$ de silagem de milho e $50 \%$ de concentrado ou $1,2 \%$ do PV em concentrado, na base da matéria seca total.

secção da veia jugular, conforme Instrução Normativa №3 do MAPA (2000). O peso médio de abate dos machos nãocastrados, castrados e fêmeas foi de 435; 396 e $372 \mathrm{~kg}$, respectivamente. $\mathrm{O}$ sangue foi recolhido em recipiente plástico, pesado e amostrado. Todas as partes constituintes do corpo animal [(cabeça, patas, cauda, couro, aparelho gastrintestinal (rúmen, retículo, omaso, abomaso, intestino delgado, intestino grosso), órgãos internos (pulmões, rins, coração, baço, fígado), gordura interna, mesentério, língua, diafragma, aparas (esôfago, traqueia, laringe, aparelho reprodutivo), e meia-carcaças esquerda e direita] foram pesadas e o trato gastrintestinal foi devidamente esvaziado e lavado previamente à sua pesagem. A carcaça foi dividida ao meio, resultando em duas meias-carcaças. Amostras de cada um desses constituintes, exceto da carcaça, foram tomadas imediatamente após sua pesagem e acondicionadas em sacos plásticos devidamente identificados.

O peso de corpo vazio (PCVZ) de cada animal foi obtido pelo somatório de todas as partes constituintes do corpo descritas acima mais o sangue. Para obtenção do peso de corpo vazio inicial dos animais que permaneceram no experimento, utilizou-se a relação PCVZ/PV média obtida nos animais-referência, dentro de cada classe sexual. As composições médias da carcaça e do corpo vazio como um todo obtidas nos animais-referência foram utilizadas para estimar as composições iniciais dos demais animais, sempre dentro de cada classe sexual separadamente.

Ao término de cada abate, as carcaças foram resfriadas a $0{ }^{\circ} \mathrm{C}$ por um período de 18 a 24 horas. As amostras do aparelho gastrintestinal, dos órgãos internos, da língua, das aparas, do mesentério, da gordura interna e do diafragma foram proporcionalmente agrupadas e pesadas, compondo uma amostra composta (denominada órgãos mais vísceras), que foi moída em seguida. O sangue amostrado foi transferido para recipientes plásticos, pesado, e levado a estufa de ventilação forçada de ar a $65^{\circ} \mathrm{C}$ para secagem. Depois de seco, foi novamente pesado e processado em moinho de bola e acondicionado em recipientes plásticos, para posterior determinação dos seus teores de matéria seca, extrato etéreo, proteína bruta e matéria mineral.

Dentro de cada tratamento, foi escolhido um animal, aleatoriamente, do qual foram obtidos a cabeça e dois membros (um anterior e um posterior). A cabeça foi dissecada em couro, tecido mole e osso e os membros, em couro, tendões e ossos. O peso do couro obtido na dissecação da cabeça e dos membros foi adicionado ao couro retirado no momento do abate, obtendo-se, assim, o peso total do couro de cada animal. O tecido mole da cabeça e os tendões dos membros foram moídos, enquanto os ossos foram serrados. Todos os tecidos foram amostrados e armazenados para posteriores análises laboratoriais. As composições física e química da cabeça e dos membros, obtidas nos animais sorteados, dentro de cada classe sexual, foram utilizadas para obtenção das composições dos demais animais de mesma classe classe sexual.

Transcorrido o resfriamento, as carcaças foram novamente pesadas e as meia-carcaças direitas de todos os animais foram dissecadas, quando houve separação dos tecidos adiposo, muscular e ósseo. O tecido adiposo foi subdividido em tecido adiposo subcutâneo e intermuscular, que foram pesados separadamente. Após a separação, os tecidos adiposo (subcutâneo e intermuscular) e muscular foram pesados e moídos separadamente. Após a moagem, obteve-se, de forma proporcional, uma amostra composta, denominada de músculo mais gordura da carcaça. Os ossos 
da carcaça foram subdivididos em três classes: ossos longos (representados pelos ossos dos membros anteriores e posteriores e da pelve), costelas e vértebras. Os ossos, dentro de cada classificação, foram pesados, serrados e amostrados separadamente. No momento do processamento das amostras da carcaça, os ossos foram pesados proporcionalmente e homogeneizados, constituindo uma amostra composta representativa da carcaça, denominada de amostra ossos da carcaça.

As amostras dos ossos e a composta músculo mais gordura foram armazenadas a $-20{ }^{\circ} \mathrm{C}$ para posteriores quantificações de seus teores de matéria seca, extrato etéreo, proteína e cinzas.

As amostras (aproximadamente $200 \mathrm{~g}$ cada) de couro, cauda, tecido mole da cabeça, osso da cabeça, tendões, osso dos membros, órgãos mais vísceras, músculo mais gordura da carcaça e ossos da carcaça foram acondicionadas em vidros com capacidade aproximada de $500 \mathrm{~mL}$, pesadas e levadas à estufa a $105^{\circ} \mathrm{C}$, por período de 48 a 96 horas, para quantificação de seu teor de matéria seca gordurosa (MSG). Posteriormente, as amostras foram pesadas novamente, tiveram a gordura removida dos vidros e foram submetidas a lavagens sucessivas com éter de petróleo, com o intuito de se obter a matéria seca pré-desengordurada (MSPD). Em seguida, foram moídas em moinho de bola, acondicionadas em recipientes plásticos e devidamente armazenadas para posteriores determinações laboratoriais dos teores de matéria seca, extrato etéreo e proteína. A gordura removida no pré-desengorduramento foi calculada pela diferença entre a MSG e a MSPD, cujo resultado foi adicionado aos obtidos para o extrato etéreo residual na MSPD, para determinação do teor total de gordura nas amostras.

As determinações de matéria seca, matéria mineral, extrato etéreo e nitrogênio total das amostras dos constituintes corporais foram realizadas de acordo com recomendações de Silva \& Queiroz (2002) e o teor de proteína bruta foi obtido pelo produto entre o nitrogênio total e o fator 5,88 (Baldwin, 1995). A partir dos teores de matéria seca, proteína, extrato etéreo e cinzas, obtidos nas amostras de todos os constituintes corporais, conforme descrito previamente, obtiveram-se os teores de água, extrato etéreo, proteína e cinzas no corpo vazio e na carcaça dos animais. A partir da composição inicial, estimada pelos animais abatidos ao início do experimento, determinou-se também a composição corporal e do ganho de peso dos animais ao longo do experimento.

As variáveis estudadas foram analisadas estatisticamente por intermédio dos programas SAS (1989) e MINITAB (1994), sendo classe sexual, nível de oferta de concentrado e a interação classe sexual × nível de oferta de concentrado os efeitos fixos considerados. Adotou-se o nível de 5\% de probabilidade para as comparações entre as médias, que foram realizadas a partir do teste Tukey.

\section{Resultados e Discussão}

A interação classe sexual $\times$ nível de oferta de concentrado não foi significativa $(\mathrm{P}>0,05)$ para nenhuma das variáveis estudadas. Dessa forma, os efeitos de classe sexual e nível de oferta de concentrado foram avaliados e discutidos independentemente.

O tecido adiposo intermuscular foi o local com deposição de $46,3 \%$ da gordura total, seguido pelo subcutâneo (27,0\%), pelo mesentérico $(18,3 \%)$ e, com menor contribuição, o depósito perirrenal $(7,58 \%)$; e somente o depósito intermuscular foi afetado $(\mathrm{P}<0,05)$ pela clase sexual; os machos não-castrados direcionaram mais gordura para esse depósito que as fêmeas; os machos castrados ficaram em posição intermediária (Tabela 3 ).

Os níveis de oferta de concentrado não afetaram $(\mathrm{P}>0,05)$ a distribuição da gordura entre os tecidos (Tabela 3). No entanto, a deposição de gordura subcutânea foi maior $(\mathrm{P}<0,05)$ nas fêmeas, seguidas dos machos castrados e, finalmente, dos machos não-castrados (Tabela 3). Butterfield (1988) revisou dados coletados em ovinos e constatou que a diferença no maior teor de gordura corporal em ovelhas em relação a carneiros adultos foi atribuído em grande parte à maior proporção de gordura subcutânea, com observado neste trabalho (Tabela 3). Mesmo com a menor participação de gordura subcutânea entre as três classes sexuais avalidas (Tabela 3), os animais não-castrados apresentaram cobertura de gordura na carcaça $(5,82 \mathrm{~mm}$; com peso médio de $435 \mathrm{~kg})$ acima do limite mínimo recomendável pela indústria frigorífica $(3,0$ $\mathrm{mm}$ ), comprovando que podem ser utilizados na obtenção de carcaças de qualidade, desde que abatidos jovens e com condições nutricionais suficientes para depositarem gordura na carcaça. No entanto, o manejo desses animais, desde a unidade produtiva, passando pelo embarque, pelo curral de espera no frigorífico e pelas etapas que antecedem ao abate em si, deve ser realizado de forma bastante criteriosa, pois são mais susceptíveis ao estresse e podem produzir carcaças com alterações metabólicas que podem comprometer a qualidade final da carne (Justino et al., 2007).

A participação do tecido adiposo intermuscular no corpo vazio foi semelhante entre as três classes sexuais, enquanto as fêmeas apresentaram maior participação de tecido adiposo perirrenal e mesentérico em relação aos 
Tabela 3 - Partição entre os principais depósitos de gordura corporal em bovinos Nelore de classes sexuais recebendo dois níveis de oferta de concentrado na dieta

\begin{tabular}{|c|c|c|c|c|c|c|c|c|c|}
\hline \multirow[t]{2}{*}{ Item } & \multicolumn{3}{|c|}{ Classe sexual } & \multicolumn{2}{|c|}{ Nível de concentrado } & \multicolumn{3}{|c|}{ Valor P } & \multirow[t]{2}{*}{$\mathrm{CV}^{1}$} \\
\hline & $\begin{array}{l}\text { Machos não- } \\
\text { castrados }\end{array}$ & $\begin{array}{l}\text { Machos } \\
\text { castrados }\end{array}$ & Fêmeas & $0,6 \% \mathrm{PV}$ & $1,2 \% \mathrm{PV}$ & $\begin{array}{l}\text { Classe } \\
\text { sexual }\end{array}$ & $\begin{array}{c}\text { Nível } \\
\text { concentrado }\end{array}$ & Interação & \\
\hline Gordura subcutânea & 26,5 & 27,6 & 29,2 & 26,9 & 28,6 & 0,37 & 0,29 & 0,39 & 3,74 \\
\hline Gordura intermuscular & $49,4 \mathrm{a}$ & $45,6 \mathrm{ab}$ & $44,0 \mathrm{~b}$ & 47,3 & 45,3 & 0,016 & 0,17 & 0,77 & 4,01 \\
\hline Gordura perirrenal & 6,82 & 8,22 & 7,70 & 7,39 & 7,77 & 0,12 & 0,49 & 0,56 & 1,34 \\
\hline Gordura subcutânea & $5,04 \mathrm{~b}$ & $5,66 \mathrm{ab}$ & $6,62 \mathrm{a}$ & 5,50 & 6,04 & 0,015 & 0,19 & 0,46 & 1,15 \\
\hline Gordura intermuscular & 9,38 & 9,34 & 9,94 & 9,57 & 9,54 & 0,50 & 0,94 & 0,75 & 1,04 \\
\hline Gordura perirrenal & $1,29 b$ & $1,68 \mathrm{a}$ & $1,75 \mathrm{a}$ & 1,49 & 1,65 & 0,007 & 0,18 & 0,44 & 0,34 \\
\hline Gordura mesentérica & $3,26 b$ & $3,77 \mathrm{ab}$ & $4,39 \mathrm{a}$ & 3,72 & 3,90 & 0,03 & 0,58 & 0,28 & 0,88 \\
\hline $\begin{array}{l}\text { Espessura de gordura } \\
\text { subcutânea, } \mathrm{mm}^{2}\end{array}$ & 5,82 & 7,28 & 8,31 & 7,30 & 6,98 & 0,17 & 0,76 & 0,90 & 2,49 \\
\hline
\end{tabular}

Médias na mesma linha, dentro de classe sexual ou nível de concentrado, seguidas por letras diferentes diferem $(\mathrm{P}<0,05)$ entre si.

${ }^{1} \mathrm{CV}=$ coeficiente de variação $;{ }^{2} \mathrm{EGS}=$ espessura de gordura subcutânea.

machos não-castrados, com os castrados, mais uma vez, apresentando valores intermediários (Tabela 3), refletindo as diferenças em relação ao peso relativo dos órgãos internos e das vísceras em relação ao peso de corpo vazio (Tabela 5) entre as três classes sexuais. Além disso, a maior participação da gordura interna nas fêmeas também ajuda a explicar sua menor taxa de crescimento em relação aos machos nãocastrados, visto que a deposição da gordura na cavidade abdominal ocorre às expensas do ganho de peso (Sprinkle et al., 1998). O tecido adiposo subcutâneo dos machos nãocastrados provavelmente ainda estava em fase hiperplásica e hipertrófica de desenvolvimento anterior à dos machos castrados e das fêmeas, enquanto o intermuscular se encontrava em fase similar de acúmulo de gordura.

A partição da deposição de gordura parece seguir uma ordem cronológica fixa. A gordura perirrenal é a primeira a ser depositada, seguida pela intermuscular, pela subcutânea e, finalmente, pela intramuscular. O desenvolvimento do tecido adiposo se dá tanto por hiperplasia (aumento no número de células), quanto por hipertrofia (aumento do tamanho dos adipócitos como resultado do acúmulo de gordura no citoplasma) (Sainz \& Hasting, 2000). Quando os animais atingem a fase de terminação, os depósitos de gordura que se desenvolvem mais precocemente (intermuscular, perirrenal e mesentérico) já completam seu desenvolvimento hiperplásico e passam a depositar gordura nos adipócitos já existentes, enquanto os depósitos subcutâneo e intramuscular continuam a recrutar novos adipócitos, ao mesmo tempo em que os preenchem com gordura.

O nível de oferta de concentrado e a interação classe sexual $\times$ nível de oferta de concentrado não tiveram efeito $(\mathrm{P}>0,05)$ na composição do peso de corpo vazio e do ganho de peso de corpo vazio (GPCVZ), nas taxas de deposição dos constituintes químicos do corpo vazio e na participação dos órgãos e das vísceras no peso de corpo vazio (Tabelas 4 e 5 ).

Fortin et al. (1980) detectaram que o efeito de sexo sobre as taxas de acréscimo dos principais constituintes químicos do corpo vazio foi dependente da raça estudada e do nível de energia da dieta. Embora a dieta com maior oferta de concentrado $(1,2 \%$ do $\mathrm{PV})$ tenha tido maior densidade energética que aquela com menor nível de oferta de concentrado $(67,91 \times 62,41 \%$ de NDT $)$, o consumo de energia, em kg de NDT/dia, não diferiu entre as classes sexuais (valor médio de 4,79 $\mathrm{kg}$ de NDT/dia), o que pode explicar a ausência de efeito da interação classe sexual $\times$ nível de oferta de concentrado sobre as taxas de acréscimo de proteína, água, extrato etéreo ou cinzas corporais. Nota-se, desta forma, que a dieta com concentrado na proporção de $0,6 \%$ do PV forneceu nutrientes suficientes para que os animais obtivessem crescimento com a mesma composição dos animais alimentados com o maior nível de concentrado. A dieta não foi, portanto, fator limitante. Jesse et al. (1976) também não observaram efeito do nível de energia dietética sobre a composição da carcaça e do peso de corpo vazio (teores de água, proteína e extrato etéreo).

A classe sexual, por outro lado, influenciou $(\mathrm{P}<0,05)$ a composição corporal e o ganho de peso de corpo vazio dos animais (Tabela 4). Embora os machos não-castrados tenham apresentado maior $(\mathrm{P}<0,05)$ taxa de crescimento e maior peso de corpo vazio $(405,5 \mathrm{~kg})$ ao final do experimento, apresentaram maior $(\mathrm{P}<0,05)$ conteúdo de proteína no peso de corpo vazio e menor teor de gordura ou extrato etéreo (Tabela 4). O teor de cinzas no peso de corpo vazio foi menor nas fêmeas $(\mathrm{P}<0,05)$, que apresentam 
carcaças com menor porcentagem de ossos $(15,25$ vs $16,62 \%)$, pois esses representam o tecido animal com maior conteúdo de matéria mineral. Além disso, o maior teor de gordura corporal também explica o menor conteúdo de cinzas no corpo vazio das fêmeas, uma vez que o tecido adiposo apresenta concentrações muito baixas de minerais (Coelho da Silva, 1995). Os machos castrados apresentaram composição do peso de corpo vazio intermediária entre os machos não-castrados e as fêmeas. Essa diferença na composição corporal final foi reflexo da composição do ganho de peso de corpo vazio (GPCVZ), já que os machos não-castrados apresentaram maior conteúdo de proteína e menor de extrato etéreo no GPCVZ que os machos castrados e as fêmeas (Tabela 4). O teor de água do ganho de corpo vazio dos machos não-castrados em relação aos castrados e às fêmeas foi quase $20 \%$ superior (Tabela 4), diferença que se aproximou muito do nível de significância $(\mathrm{P}<0,053)$. Como o ganho de peso de corpo vazio dos machos não-castrados foi mais proteico $(\mathrm{P}<0,05)$ em relação aos machos castrados e as fêmeas (Tabela 4), resultado da maior deposição de proteína (Tabela 5), a maior participação de água no ganho de corpo vazio dos animais não-castrados é uma consequência, visto que a deposição proteica está intimamente relacionada à deposição de água (Clawson et al., 1991).

A taxa de deposição de proteína corporal foi maior $(\mathrm{P}<0,05)$ nos machos não-castrados $(147,9 \mathrm{~g} \mathrm{~PB} /$ dia $)$ em relação aos machos castrados e às fêmeas (média de 81,05 g PB/dia), mas não foi detectada diferença significativa entre as classe sexuais $(\mathrm{P}>0,05)$ para a taxa de deposição de extrato etéreo corporal (Tabela 5). Embora a diferença absoluta entre as taxas de deposição de extrato etéreo no corpo vazio observada nos machos não-castrados em relação aos castrados tenha sido superior em relação às taxas de deposição de proteína $(60,7 \mathrm{~g} /$ dia, para extrato etéreo e $57,5 \mathrm{~g} /$ dia para proteína), em termos relativos, essas diferenças corresponderam a 15 e $39 \%$, respectivamente, o que explica a significância $(\mathrm{P}<0,05)$ da diferença entre as duas classes sexuais para a taxa de deposição de proteína e a ausência de diferença significativa $(\mathrm{P}>0,05)$ para o extrato etéreo (Tabela 5). Assim, parece que a castração não ampliou a deposição de gordura, mas reduziu a deposição de proteína, fazendo com que, por diluição da proteína corporal, os machos castrados apresentassem melhor acabamento de carcaça. Machos não-castrados apresentaram menor participação de órgãos mais vísceras no peso de corpo vazio que as fêmeas; os machos castrados ficaram em posição intermediária (Tabela 5). Embora as fêmeas tenham apresentado maior conteúdo de gordura visceral que os machos não-castrados, a taxa de deposição de gordura nas vísceras não diferiu $(\mathrm{P}>0,05)$ entre as três classes sexuais. Essa maior participação da gordura visceral no peso de corpo vazio das fêmas foi reflexo da maior quantidade de órgãos e vísceras em relação ao corpo vazio. Como as fêmeas apresentaram maior consumo de matéria seca (Paulino et al., 2008), e como o tamanho do trato gastrintestinal aumenta com o aumento do consumo de alimentos e nutrientes (Sainz \& Bentley, 1997), esse comportamento pode ser considerado normal.

A maior taxa de acréscimo de proteína no corpo vazio de machos não-castrados em relação aos machos castrados e às fêmeas esteve relacionada à secreção de testosterona (Fletcher et al., 1986) e o efeito anabólico desse hormônio sobre a proteína corporal é provavelmente expresso pela redução na degradação protéica nos músculos (Lobley et al., 1990; Morgan et al., 1993) e, menos intensamente, pelo aumento na taxa de síntese proteica

Tabela 4 - Composição química do peso de corpo vazio e do ganho de corpo vazio de bovinos Nelore de três classes sexuais recebendo dois níveis de concentrado na dieta

\begin{tabular}{|c|c|c|c|c|c|c|c|c|c|}
\hline \multirow[t]{2}{*}{ Item } & \multicolumn{3}{|c|}{ Classe sexual } & \multicolumn{2}{|c|}{ Nível de oferta de concentrado } & \multicolumn{3}{|c|}{ Valor $\mathrm{P}$} & \multirow[t]{2}{*}{$\mathrm{CV}^{1}$} \\
\hline & $\begin{array}{l}\text { Machos não- } \\
\text { castrados }\end{array}$ & $\begin{array}{l}\text { Machos } \\
\text { castrados }\end{array}$ & Fêmeas & $0,6 \% \mathrm{PV}$ & $1,2 \% \mathrm{PV}$ & $\begin{array}{l}\text { Classe } \\
\text { sexual }\end{array}$ & $\begin{array}{c}\text { Nível } \\
\text { concentrado }\end{array}$ & Interação & \\
\hline \multicolumn{10}{|c|}{ Composição química do peso de corpo vazio, \% } \\
\hline Proteína & $16,66 \mathrm{a}$ & $15,98 \mathrm{ab}$ & $15,38 b$ & 16,03 & 15,98 & 0,004 & 0,85 & 0,55 & 0,81 \\
\hline Extrato etéreo & $21,23 b$ & $23,48 \mathrm{ab}$ & $25,04 \mathrm{a}$ & 23,17 & 23,34 & 0,017 & 0,86 & 0,73 & 2,69 \\
\hline Água & 55,46 & 53,74 & 53,14 & 54,19 & 54,03 & 0,051 & 0,83 & 0,83 & 1,90 \\
\hline Cinzas & $4,80 \mathrm{a}$ & $4,82 \mathrm{a}$ & $4,44 b$ & 4,71 & 4,66 & 0,02 & 0,65 & 0,92 & 0,30 \\
\hline \multicolumn{10}{|c|}{ Composição química do ganho de corpo vazio, \% } \\
\hline Proteína & $15,41 \mathrm{a}$ & $11,19 b$ & $9,53 \mathrm{~b}$ & 11,91 & 12,18 & 0,002 & 0,82 & 0,42 & 3,63 \\
\hline Extrato etéreo & $36,8 \mathrm{~b}$ & $50,3 \mathrm{a}$ & $48,4 \mathrm{a}$ & 46,0 & 44,4 & 0,04 & 0,71 & 0,46 & 11,41 \\
\hline Água & 45,6 & 36,0 & 37,9 & 39,4 & 40,3 & 0,053 & 0,76 & 0,59 & 8,20 \\
\hline Cinzas & $2,35 \mathrm{ab}$ & $1,70 b$ & $3,34 \mathrm{a}$ & 2,49 & 2,44 & 0,03 & 0,91 & 0,66 & 1,22 \\
\hline
\end{tabular}

Médias na mesma linha, dentro de classe sexual ou nível de concentrado, seguidas de letras diferentes, diferem entre si $(\mathrm{P}<0,05)$.

${ }^{1} \mathrm{CV}=$ coeficiente de variação. 
Tabela 5 - Taxas de deposição dos constituintes químicos do peso de corpo vazio e participação de alguns tecidos no corpo vazio de bovinos Nelore de diferentes classes sexuais recebendo dois níveis de concentrado na dieta

\begin{tabular}{|c|c|c|c|c|c|c|c|c|c|}
\hline \multirow[t]{2}{*}{ Item } & \multicolumn{3}{|c|}{ Classe sexual } & \multicolumn{2}{|c|}{ Nível de oferta de concentrado } & \multicolumn{3}{|c|}{ Valor $\mathrm{P}$} & \multirow[t]{2}{*}{$\mathrm{CV}^{1}$} \\
\hline & $\begin{array}{l}\text { Machos não- } \\
\text { castrados }\end{array}$ & $\begin{array}{l}\text { Machos } \\
\text { castrados }\end{array}$ & Fêmeas & $0,6 \% \mathrm{PV}$ & $1,2 \% \mathrm{PV}$ & $\begin{array}{l}\text { Classe } \\
\text { sexual }\end{array}$ & $\begin{array}{c}\text { Nível } \\
\text { concentrado }\end{array}$ & Interação & \\
\hline Proteína & $147,9 \mathrm{a}$ & $90,4 b$ & $71,7 \mathrm{~b}$ & 100,6 & 106,0 & $<0,0001$ & 0,67 & 0,25 & 44,22 \\
\hline Extrato etéreo & 342,6 & 403,3 & 356,9 & 365,8 & 369,3 & 0,35 & 0,92 & 0,65 & 81,60 \\
\hline Água & $434 \mathrm{a}$ & $293 b$ & $281 \mathrm{~b}$ & 327 & 345 & 0,003 & 0,60 & 0,23 & 106,5 \\
\hline $\begin{array}{l}\text { Órgãos + vísceras, } \\
\% \text { do PCVZ }\end{array}$ & $14,13 b$ & $15,13 \mathrm{ab}$ & $15,92 \mathrm{a}$ & 14,90 & 15,21 & 0,006 & 0,44 & 0,94 & 1,14 \\
\hline
\end{tabular}

Médias na mesma linha, dentro de classe sexual ou nível de concentrado, seguidas por letras diferentes, diferem entre si (P<0,05).

${ }^{1} \mathrm{CV}=$ coeficiente de variação

(Martinez et al., 1984). No entanto, a testosterona estimula a proliferação das células-satélites, células indiferenciadas que se localizam de forma adjacente às fibras musculares (Spencer, 1985). As células-satélites se fundem então às fibras musculares, doando seus núcleos, o que aumenta de forma significativa a capacidade de síntese proteica do músculo(Florini, 1987).

A gordura é o principal consituinte do corpo vazio que causa variações na composição corporal, uma vez que flutuações observadas nos demais constituintes corporais ocorrem como reflexo das mudanças na quantidade de gordura presente no corpo (Reid et al. 1972). Diferenças na composição química corporal resultam de variações observadas entre os animais quanto à diferença cronológica temporal ou de peso em que ocorre o iníco da fase de deposição mais acentuada de gordura, o que, geralmente, ocorre após a puberdade, e à taxa de deposição de gordura, ou uma combinação de ambos (Berg \& Butterfield, 1976). Como as taxas de deposição desse componente não foram afetadas pela classe sexual (Tabela 5), as diferenças no teor de gordura no peso de corpo vazio entre os machos nãocastrados, os machos castrados e as fêmeas ocorreram em virtude dos tempos em que os animais atingiram a fase de rápido crescimento do tecido adiposo. As fêmeas, por serem de maturidade mais precoce, atingem esse tempo de maior ímpeto de deposição de gordura mais cedo que os machos.

\section{Conclusões}

A interação classe sexual $\times$ nível de oferta de concentrado não é importante para as principais características de composição corporal de bovinos Nelore consumindo até 1,2\% do PV em concentrado. Machos não-castrados depositam proteína de forma mais pronunciada no corpo vazio em comparação a machos castrados e fêmeas. Machos não-castrados apresentam maior teor de proteína e menor de gordura no corpo vazio e no ganho de peso de corpo vazio, mesmo tendo mesma taxa de deposição de gordura de machos castrados e fêmeas.

\section{Agradecimentos}

Aos funcionários do Laboratório Animal e do Laboratório de Nutrição Animal do Departamento de Zootecnia da Universidade Federal de Viçosa; e aos estagiários e bolsistas de iniciação científica que contribuíram para execução deste trabalho.

\section{Literatura Citada}

BALDWIN, R.L. Modeling ruminant digestion and metabolism. London: Chapman and Hall, 1995. 592p.

BONILHA, S.F.M.; PACKER, I.U.; FIGUEIREDO, L.A. et al. Efeito da seleção para peso pós-desmame sobre a composição corporal de bovinos. Revista Brasileira de Zootecnia, v.36, n.5, p.1282-1287, 2007.

BERG, R.T.; BUTTERFIELD, R.M. New concepts of cattle growth. 1.ed. Sydney: Sydney University Press, 1976. 240p.

BUTTERFIELD, R.M. New concepts of sheep growth. Sydney: Sydney University, 1988. 168p.

CLAWSON, A.J.; GARLICH, J.D.; COFFEY, M.T. et al. Nutritional, physiological, genetic, sex, and age effects on fat-free dry matter composition of the body in avian, fish, and mammalian species: a review. Journal of Animal Science, v.69, n.9, p.3617-3644, 1991.

COCHRAN, R.C.; ADAMS, D.C.; WALLACE, J.D. et al. Predicting digestibility of different diets with internal markers: evaluation of four potential markers. Journal of Animal Science, v.63, n.5, p.1476-1483, 1986.

COELHO DA SILVA, J.F. Exigências de macroelementos inorgânicos para bovinos: o sistema ARC/AFRC e a experiência mo Brasil. In: SIMPÓSIO INTERNACIONAL SOBRE EXIGÊNCIAS NUTRICIONAIS DE RUMINANTES, 1., 1995, Viçosa, MG. Anais... Viçosa, MG: Universidade Federal de Viçosa, 1995. p. 467-504. 
COLEMAN, S.W.; EVANS, B.C.; GUENTHER, J.J. Body and carcass composition of Angus and Charolais steers as affected by age and nutrition. Journal of Animal Science, v.71, n.1, p.86-95, 1993.

FLETCHER, J.M.; LOBLEY, G.E.; CONNELL, G.E. Effects on growth and body composition of androgen deprivation by castration or autoimmunization to LH-releasing hormone in the male rat under conditions of controlled food intake. Endocrinology, v.110, n.1, p.97-102, 1986.

FLORINI, J.R. Hormonal control of muscle growth. Muscle \& Nerve, v. 10, n.7, p.577-598, 1987.

FORTIN, A.; SIMPFENDORFER, S.; REID, J.T. et al. Effect of level of energy intake and influence of breed and sex on the chemical composition of cattle. Journal of Animal Science, v.51, n.3, p.604-614, 1980.

HALL, M.B. Calculation of non-structural carbohydrate content of feeds that contain non-protein nitrogen. Gainesville: University of Florida, 2000. p.A-25 (Bulletin, 339).

HUNTER, R.A.; SIEBERT, B.D. Utilization of low-quality roughage by Bos taurus and Bos indicus cattle. 2. The effects of rumen-degradable nitrogen and sulphur on voluntary food intake and rumen characteristics. British Journal of Nutrition, v.53, n.3, p.649-656, 1985.

JESSE, G.W.; THOMPSON, G.B.; CLARK, J.L. et al. Effects of ration energy and slaughter weight on composition of empty body and carcass gain of beef cattle. Journal of Animal Science, v.43, n.2, p.418-425, 1976 .

JUSTINO, R.O.; PAULINO, P.V.R.; BELO, I.C.S. Efeitos de classe sexual e grau de acabamento sobre $\mathrm{pH}$ e incidência de contusões na carcaça de bovinos. In: CONGRESSO BRASILEIRO DE CIÊNCIA E TECNOLOGIA DE CARNES, 4., 2007, Campinas. Anais... Campinas: Centro de Pesquisa e Desenvolvimento de Carnes, 2007. p.304-306.

KEMPSTER, A.J. Fat partition and distribution in the carcasses of cattle, sheep and pigs: a review. Meat Science, v.5, n.2, p.83-98, 1981.

LICITRA, G.; HERNANDEZ, T.M.; VAN SOEST, P.J. Standardization of procedures for nitrogen fractionation of ruminant feeds. Animal Feed Science and Tecnhology, v.57, p.347-358, 1996

LOBley, G.E.; CONNELl, A.; MILnE, E. Muscle protein synthesis in response to testosterone administration in wether lambs. British Journal of Nutrition, v.64, n.3, p.691-704, 1990 .

LOHMAN, T.G. Biological variation in body composition. Journal of Animal Science, v.32, n.4, p.647-653, 1971

MINISTÉRIO DA AGRICULTURA, PECUÁRIA E ABASTECIMENTO - MAPA. Instrução normativa $N^{0}$ 3, de 17 de janeiro de 2000: Regulamento técnico de métodos de insensibilização para o abate humanitário de animais de açougue. Brasília: 2000. 6p.

MARTINEZ, J.A.; BUTTERRY, P.J.; PEARSON, J.T. The mode of action of anabolic agents: the effect of testosterone on muscle protein metabolism in the female rat. British Journal of Nutrition, v.52, n.3, p.515-521, 1984.

MINITAB. Minitab reference manual. Release 10 for Windows. Minitab Statistical Software. State College: 1994. 140p.

MORGAN, J.B.; WHEELER, T.L.; KOOHMARAIE, M. et al. Effect of castration on myofibrillar protein turnover, endogenous proteinase activities, and muscle growth in bovine skeletal muscle. Journal of Animal Science, v.71, n.2, p.408-414, 1993

NATIONAL RESEARCH COUNCIL - NRC. Nutrient requirements of beef cattle. 7.rev.ed. Washington, D.C.: National Academic Press, 2000. 242p.
NATIONAL RESEARCH COUNCIL - NRC. Nutrient requirements of dairy cattle. 7. ed. Washington, D.C.: National Academic Press, 2001. 381p.

OLD, C.A.; GARRETT, W.N. Effects of energy intake on energetic efficiency and body composition of beef steers differing in size at maturity. Journal of Animal Science, v.65, n.5, p.1371-1380, 1987.

OLIVEIRA, R.F.M.; FONTES, C.A.A.; SILVA, J.F.C. Consumo e digestibilidade de dietas com duas proporções de concentrados fornecidas a bovinos de três grupos genéticos. Revista Brasileira de Zootecnia, v.20, n.5, p.513-521, 1991.

PAULINO, P.V.R.; VALADARES FILHOS, S.C.; DETMANN, E. et al. Desempenho produtivos de bovinos Nelore de diferentes classes sexuais alimentados com dietas contendo dois níveis de oferta de concentrado. Revista Brasileira de Zootecnia, v.37, n.6, p.1079-1087, 2008.

PURCHAS, R.W. Effect of sex and castration on growth and composition. In: PEARSON, A.M.; DUTSON, T.R. (Eds.) Growth regulation in farm animals - advances in meat research. 1.ed. London, 1991. p.203-254

PUTRINO, S.M.; LEME, P.R.; LUZ E SILVA, S. et al. Digestibilidade aparente de dietas com níveis crescentes de concentrado em novilhos Brangus e Nelore. Arquivo Brasileiro de Medicina Veterinária e Zootecnia, v.59, n.2, p.406-413, 2007.

REID, J.T.; BENSADOUN, L.S.; BULL, J.H. et al. Some peculiarities in the body composition of animals: interspecific, sex, age and the influence of nutrition. In: Body composition in animals and man. 1.ed. Washington: National Academy Press, 1972. p. 19-44.

SAINZ, R.D.; BENTLEY, B.E. Visceral organ mass and cellularity in growth-restricted and refed beef steers. Journal of Animal Science, v.75, n.5, p.1229-1236, 1997.

SAINZ, R.D.; HASTING, E. Simulation of the development of adipose tissue in beef cattle. In: McNAMARA, J.P.; FRANCE, J.; BEEVER, D.E. (Eds.). Modelling nutrient utilization in farm animals. 1.ed. New York: CAB International, 2000 p. $175-182$.

SILVA, D,J.; QUEIROZ, A.C. Análise de alimentos (Métodos químicos e biológicos). 3.ed. Viçosa, MG: Editora UFV, 2002. 235p.

SPENCER, G.S.G. Hormonal systems regulating growth. A review. Livestock Production Science, v.12, n.1, p.31-46, 1985.

SPRINKLE, J.E.; FERRELL, C.L.; HOLLOWAY, J.W. et al. Adipose tissue partitioning of limit-fed beef cattle and beef cattle with ad libitum access to feed differing in adaptation to heat. Journal of Animal Science, v.76, n.3, p.665-673, 1998.

STATISTICAL ANALYSIS SYSTEM - SAS. SAS/STAT ${ }^{\circledR}$ user's guide. Version 6, 4.ed. Cary: 1989.

VALADARES FILHO, S.C.; PAULINO, P.V.R.; MAGALHÃES, K.A Exigências nutricionais de bovinos de corte no Brasil. In: CONGRESSO BRASILEIRO DE ZOOTECNIA - ZOOTEC, 10. 2005, Campo Grande. Anais... Campo Grande: Universidade Estadual do Mato Grosso do Sul, 2005. (CD-ROM).

VAN SOEST, P.J.; ROBERTSON, J.B. Systems of analysis for evaluating fibrous feeds. In: PIGDEN, W.J.; BALCH, C.C.; GRAHAM, M. (Eds.). Standardization of analytical methodology for feeds. 1.ed. Ottawa: International Development Research Centre, 1980. p.49.

VAN SOEST, P.J.; ROBERTSON, J.B.; LEWIS, B.A. Methods for dietary fiber, neutral detergent fiber, and nonstarch polyssacarides in relation to animal nutrition. Journal of Animal Science, v.74, n.10, p.3583-3597, 1991.

WILLIAMS, C.B. Technical note: a dynamic model to predict the composition of fat-free matter gains in cattle. Journal of Animal Science, v.83, n.6, p.1262-1266, 2005. 